\title{
Proposta de uma sistemática de gestão de requisitos para o processo de desenvolvimento de produtos sustentáveis
}

\author{
Ângela Maria Marxa,*, lstefani Carísio de Paula ${ }^{\mathrm{b}}$ \\ a,*amarx@producao.ufrgs.br, PPGEP/UFRGS, Brasil \\ bistefani@producao.ufrgs.br, PPGEP/UFRGS, Brasil
}

\begin{abstract}
Resumo
Este trabalho apresenta uma proposta para auxiliar o Processo de Desenvolvimento de Produtos (PDP) sustentáveis por meio da gestão de requisitos. A sistemática proposta é formada por três etapas e 18 tarefas que visam assegurar a consideração de aspectos ambientais, econômicos e sociais. As etapas 1 e 2 são de caráter estratégico e definem os requisitos do negócio sustentável. A etapa 3 consiste em atividades relacionadas aos requisitos do sistema-produto sustentável em desenvolvimento. A proposta preenche as lacunas encontradas na literatura, que são a inclusão de requisitos de diversos stakeholders para os diferentes elementos do sistema-produto, a inserção de mecanismos para análise de conflitos e controle de mudanças dos requisitos, o aumento na iteratividade da gestão de requisitos e a inserção de requisitos do negócio para alinhar o PDP às estratégias organizacionais. 0 resultado é uma sistemática genérica aplicável tanto a produtos sustentáveis quanto a produtos convencionais.
\end{abstract}

Palavras-chave

Sustentabilidade. Gestão de requisitos. Desenvolvimento de produto.

\section{Introdução}

A importância do desenvolvimento sustentável foi formalmente declarada em 1987 pelo relatório de Brundtland (WORLD..., 1987; SEYFANG, 2003), desencadeando o aumento das pressões legais, financeiras e mercadológicas para o desenvolvimento de produtos, serviços e processos sustentáveis (MAXWELL; VORST, 2003). De acordo com Seliger, Kernbaum e Zettl (2006), o desafio da sustentabilidade demanda uma quebra de paradigma na aplicação da engenharia, com o aumento da produtividade no uso de recursos para atender às necessidades humanas, sem exceder os limites ecológicos do planeta.

Em uma abordagem sustentável, produtos, serviços e processos devem ser concebidos considerando as questões sociais, ambientais e econômicas relacionadas a todo o seu ciclo de vida em uma linha de base tripla (Triple Bottom-Line - TBL) (SELIGER; MERTINS, 2007; LUTTROPP; KARLSSON, 2001).
Portanto, o desenvolvimento de novos produtos sustentáveis é uma tarefa complexa que requer o projeto equilibrado dos diferentes elementos de produção e consumo, dentro de um sistema que inclui diversos stakeholders (partes interessadas). Esses stakeholders incluem os usuários finais, a comunidade local, o governo, organismos não governamentais e todos aqueles com interesses relacionados às diferentes fases do ciclo de vida do produto.

Assim, a complexidade do Processo de Desenvolvimento de Produto (PDP) sustentável deve-se, em grande parte, ao volume de informação que serve de entrada para o projeto de um novo produto. Entre essas informações estão as demandas dos diversos stakeholders, além de fatores políticos, tecnológicos, sociais, ambientais e econômicos (BAXTER, 1996; MARX, 2009). Compreender, traduzir e balancear as 
necessidades desses stakeholders são fundamentais para evitar problemas decorrentes da deficiência no levantamento dos respectivos requisitos e da consequente definição inadequada do produto (TSENG; JIAO, 1997; YOUNG, 2003; CREVELING; SLUTSKY; ANTIS, 2003).

Considerando isso, pode-se assumir que um gerenciamento adequado dos requisitos contribui para o PDP sustentável, uma vez que a qualidade dos requisitos gerados tem grande impacto sobre todo o sistema. Além disso, a consideração de requisitos ambientais e sociais pode impor limites a outros critérios relevantes (LABUSCHAGNE; BRENT; ERCK, 2005), razão que justifica a adoção de métodos estruturados específicos para a definição, a negociação e o monitoramento dos requisitos de todo o sistema necessário para a criação de um produto sustentável.

De fato, os modelos referenciais de PDP apresentam diversas atividades relacionadas ao desdobramento das informações no projeto de produto, o que inclui, entre outras coisas, o desdobramento dos requisitos do produto. No entanto, a gestão de requisitos no PDP é um tema esparso e pouco estruturado na literatura. A exceção é a área de Desenvolvimento de Sistemas de Informação (DSI), em que o alto nível de customização dos projetos e a existência de múltiplos stakeholders com demandas distintas levaram à criação de processos específicos para tratar e gerenciar os requisitos de software, denominados Engenharia de Requisitos (ER) e Gestão de Requisitos (GR) (KOTONYA; SOMMERVILLE, 2000; ALVES, 2001; YOUNG, 2003; PARVIAINEN; TIHINEN; SOLINGEN, 2005; SOMMERVILLE, 2007). Da mesma forma, o gerenciamento adequado dos requisitos também é necessário no PDP de produtos sustentáveis e inovadores, podendo-se afirmar que, quanto mais inovadora a oportunidade, maiores as chances de mudanças significativas nos requisitos do produto.

Este artigo tem como objetivo apresentar a construção de uma sistemática de gestão de requisitos adequada ao PDP sustentável, de forma a facilitar a consideração de requisitos ambientais, sociais e econômicos no desenvolvimento de soluções efetivamente sustentáveis. A construção dessa sistemática é resultado do estudo da literatura, da comparação entre as atividades relacionadas aos requisitos em modelos de PDP e DSI e da análise das lacunas encontradas nesses modelos. 0 artigo apresenta, ainda, o referencial teórico sobre o qual a pesquisa foi embasada, a metodologia empregada na construção da proposta, a discussão dos resultados e considerações finais.

\section{Referencial teórico}

Produtos sustentáveis podem ser definidos como soluções que atendem às necessidades e demandas sociais, minimizando impactos negativos e maximizando impactos positivos nas dimensões ambiental, econômica, social e ética ao longo de seu ciclo de vida (WEENEN, 1995; LUTTROPP; KARLSON, 2001; DIEHL; BREZET, 2004). Assim, a abordagem do ciclo de vida constitui-se como uma premissa para que um produto seja considerado sustentável, uma vez que a dimensão ambiental da sustentabilidade só pode ser alcançada com a redução significativa dos impactos causados pela extração, transformação, utilização e reutilização dos materiais.

As questões centrais do projeto de um produto sustentável são: (i) a atenção aos volumes de produção e consumo; (ii) a ênfase no ciclo de vida, especialmente para o projeto de soluções que facilitem o reaproveitamento do produto/material; (iii) a concepção dos sistemas relacionados, como embalagens e logística; e (iv) a compatibilidade ambiental, com a utilização de recursos locais e sua disponibilidade a longo prazo (WEENEN, 1995; GUIMARÃES, 2006). Por esse motivo, quando se trata de sustentabilidade, parece adequado ampliar o conceito de produto para o de sistema-produto, uma vez que existe a necessidade de projetar conjuntamente os demais elementos do sistema de produção e consumo, o que inclui a tecnologia, os processos, o negócio e os serviços relacionados.

A Figura 1 apresenta um esquema de ciclo de vida do produto, considerando o recolhimento e a reutilização dos materiais após o seu fim de vida. Nesta abordagem, conhecida como "do berço ao berço" (cradle to cradle) (McDONOUGH; BRAUNGART, 2002), os produtos são concebidos para assumir outra forma ou função após o descarte. Em outras palavras, produtos e processos são caracterizados por ciclos artificiais (quando não biodegradáveis) que não causam distúrbios significativos ao meio ambiente.

De acordo com a literatura, o percurso histórico para a produção sustentável evoluiu do tratamento da poluição com as soluções fim de tubo, passando pela adoção de tecnologias limpas e pelo redesign ambiental dos produtos até abordagens recentes ligadas à desmaterialização da posse (KAZMIERCZYK, 2002; JOHANSSON, 2002; DIEHL; BREZET, 2004; MANZINI; VEZZOLI, 2005). Essa evolução não ocorreu de forma linear, embora muitos dos conceitos sejam cumulativos e muitas abordagens tenham englobado suas predecessoras, como apresentado a seguir. 


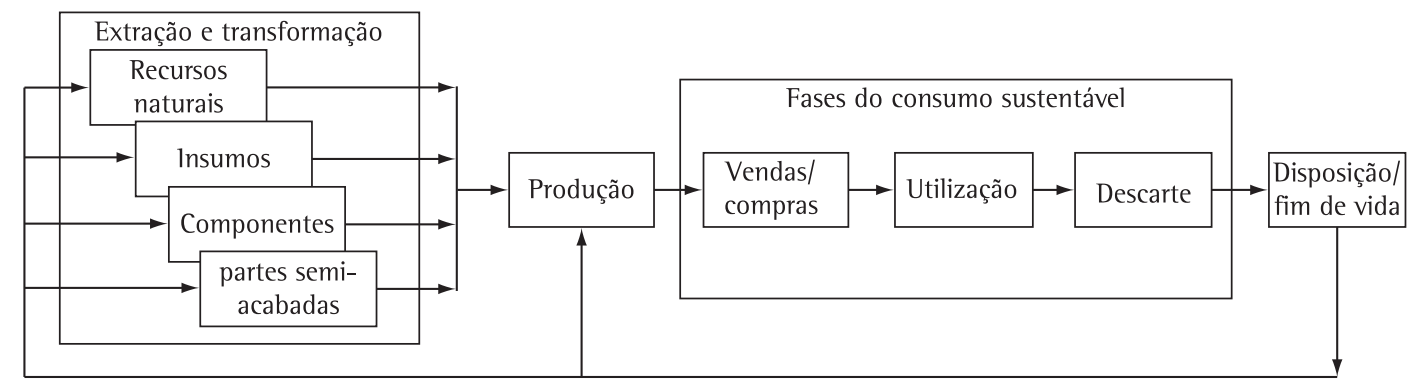

Figura 1. Ciclo de vida do produto, com as setas representando o processo de transporte. Fonte: adaptado de Hauschild, Jeswiet e Alting (2005).

Inicialmente, o esforço para evitar a poluição por meio do controle e melhoria dos processos originou a criação de uma série de diretrizes para a redução dos impactos ambientais nas fases de projeto, produção e utilização do produto, a exemplo do design para o meio ambiente (Design for Environment - DfE) (FIKSEL, 1993), do Manual de Ecodesign do Programa das Nações Unidas para o Meio Ambiente (PNUMA) (BREZET; HEMEL, 1997) e do conjunto de normas ISO 14000, estas últimas focadas na gestão ambiental das empresas (INTERNATIONAL..., 2009). Nas últimas décadas, a preocupação ambiental foi ampliada para a perspectiva do ciclo de vida do produto, incluindo também as fases de extração e transformação da matéria-prima e de consumo e reutilização dos produtos. Essa abordagem holística de sustentabilidade ambiental encontra-se presente no método ZERI (Zero Emissions Research \& Initiative) (PAULl, 1998), na certificação Cradle to Cradle (McDONOUGH; BRAUNGART, 2002) e nos conceitos de ecologia industrial (FROSCH; GALLOPOULOS, 1989) e de logística reversa (TIBBEN-LEMBKE, 2002).

Subsequentemente, as preocupações relativas às questões sociais e econômicas da sustentabilidade também passaram a ser consideradas durante o desenvolvimento de produtos, com a intenção de obter soluções genuinamente sustentáveis que consideram as três principais dimensões da sustentabilidade, a exemplo do design para a sustentabilidade (Design for Sustainability - DfS) (DIEHL; BREZET, 2004). Abordagens mais recentes incluem, ainda, a criação de novos modelos de negócio, centrados na redução do consumo e no aumento da oferta de serviços para promover o que é conhecido como "a desmaterialização do produto", a exemplo dos sistemas produto-serviço (Product Service System - PSS) (MANZINI; VEZZOLl, 2002; TUKKER; TISCHNER, 2006).

\subsection{Requisitos no desenvolvimento de produtos}

A definição de um produto é, geralmente, representada por uma lista de requisitos, também conhecida por especificações do produto ou valores-alvo (JIAO; TSENG, 1999). Essa informação é um mix de valores quantitativos e descrições qualitativas do produto, na maioria das vezes obtidos diretamente do cliente final, o que no PDP é conhecido como a voz do cliente (Voice of Customer - VOC) (COOPER, 1994; CLAUSING, 1994; BAXTER, 1996; CREVELING; SLUTSKY; ANTIS, 2003). De acordo com Tseng e Jiao (1997) e Creveling, Slutsky e Antis (2003), há muita confusão no processo de definição do produto, incluindo desacertos conceituais, problemas na definição dos requisitos e falta de mapeamento dos requisitos para os parâmetros de projeto.

Os requisitos podem ser conceituados de diversas maneiras (PAHL; BEITZ, 1996; ROOZENBURG; EEKELS, 1996; KOTONYA; SOMMERVILLE, 2000; YOUNG, 2003; PARVIAINEN; TIHINEN; SOLINGEN, 2005; ROZENFELD et al., 2006). Para efeitos deste trabalho, adota-se a seguinte definição: requisito é uma funcionalidade que o sistema-produto deve ter para satisfazer uma necessidade ou para alcançar um objetivo do stakeholder, sendo qualificado por condições mensuráveis e limitado por restrições.

Os requisitos podem ser classificados em dois grandes grupos: requisitos funcionais e requisitos não funcionais (KOTONYA; SOMMERVILLE, 2000; YOUNG, 20003; PARVIAINEN; TIHINEN; SOLINGEN, 2005). Os requisitos funcionais, também denominados requisitos técnicos, são aqueles que especificam as entradas e saídas de um sistema, isto é, as ações que o sistema deve ser capaz de executar, sem considerar restrições físicas (PARVIAINEN; TIHINEN; SOLINGEN, 2005; ROZENFELD et al., 2006). 
Os requisitos denominados não funcionais, por sua vez, definem as qualidades e os atributos do sistema como um todo, impondo ressalvas para o produto e o processo de desenvolvimento, como os requisitos legais, por exemplo. 0 fato de constituírem restrições para o sistema faz com que esse tipo de requisitos seja de importância crítica (KOTONYA; SOMMERVILLE, 2000; LABUSCHAGNE; BRENT; ERCK, 2005).

Diversos autores concordam que os requisitos, independente da denominação adotada, devem ser escritos de forma objetiva e de maneira padronizada para que sejam compreendidos por todos os envolvidos no projeto, incluindo parceiros de desenvolvimento e fornecedores (CLAUSING, 1994; PAHL; BEITZ, 1996; SOMMERVILLE, 2007). No entanto, é necessário redigir adequadamente os requisitos, para evitar interpretações errôneas das necessidades dos clientes ou expressar ideias redundantes, inconsistentes, inexequíveis ou mesmo soluções de projeto (ROOZENBURG; EEKELS, 1996; PAHL; BEITZ, 1996; AKAO, 1997; KOTONYA; SOMMERVILLE, 2000; YOUNG, 2003).

\subsection{Sistematização dos requisitos no PDP e DSI}

A literatura apresenta uma diversidade de modelos de referência para o desenvolvimento de produtos e serviços. Esses modelos diferem em relação à sua abordagem, que pode estar voltada para a gestão do PDP (CRAWFORD; BENEDETTO, 2000; ROZENFELD et al., 2006), para o projeto físico do produto (PAHL; BEITZ, 1996; ROOZENBURG; EEKELS, 1996; ULRICH; EPPINGER, 2000), para a qualidade (CLAUSING, 1994; CREVELING; SLUTSKY; ANTIS, 2003), para o meio ambiente (ABELE; ANDERL; BIRKHOFER, 2005; MANZINI; VEZOLLI, 2005), para a combinação de produtos e serviços (MONT, 2002; HALEN; VEZZOLI; WIMMER, 2005), entre outras. Independente do enfoque adotado, a maioria dos modelos apresenta uma fase de identificação de ideias e oportunidades, seguida pelo desenvolvimento do conceito e o detalhamento do projeto, seguindo até o lançamento e o acompanhamento do produto ou serviço no mercado.

Em função dessa diversidade, os modelos referenciais apresentam diferenças no tratamento das informações ao longo do PDP, e, consequentemente, nas atividades relacionadas aos requisitos. Naturalmente, modelos com maior número de fases apresentam maior número de atividades, como é o caso do modelo proposto por
Rozenfeld et al. (2006). Em geral, os requisitos de um produto são originados a partir das demandas do mercado, principalmente do cliente final, e desdobrados ao longo das demais fases do processo (CLAUSING, 1994; ULRICH; EPPINGER, 2000). Outros requisitos, no entanto, emergem ao longo do PDP em função do desdobramento natural das informações ou pelo esclarecimento de demandas inicialmente mal formuladas (PAHL; BEITZ, 1996; CREVELING; SLUTSKY; ANTIS, 2003).

Antes de iniciar o projeto do produto, as demandas e necessidades provenientes da VOC devem ser esclarecidas, uma vez que influenciam o desdobramento do projeto e determinam o layout básico do produto (PAHL et al., 2005), atividade que pode ser observada em muitos dos modelos (CLAUSING, 1994; PAHL; BEITZ, 1996; ROOZENBURG; EEKELS, 1996). Essa organização das informações no início do PDP pode ser feita de diversas maneiras, sendo comum o emprego de métodos como o desdobramento da função qualidade (Quality Function Deployment - QFD) (CLAUSING, 1994; AKAO, 1997) e a análise de atributos (CRAWFORD; BENEDETTO, 2000), além do emprego de listas de requisitos (PAHL; BEITZ, 1996; JIA0; TSENG, 1999; ABELE; ANDERL; BIRKHOFER, 2005).

Após a organização inicial dos requisitos, é possível realizar o seu desdobramento em requisitos técnicos (CLAUSING, 1994; AKAO, 1997), definir as especificações e valores-alvo para o produto (ULRICH; EPPINGER, 2000) e relacioná-los a funções ao realizar o desdobramento funcional do produto (PAHL; BEITZ, 1996; ROZENFELD et al., 2006). Todas essas alternativas representam maneiras de alocar os requisitos às partes do produto a que dizem respeito. Uma vez realizada essa tarefa, o produto está definido e as atividades relativas aos requisitos, na maioria dos modelos citados anteriormente, encerradas. Em geral, os modelos de PDP não apresentam mecanismos para o gerenciamento dos requisitos, com exceção daqueles intrínsecos aos métodos utilizados, como é o caso do QFD, que permite rastrear a origem dos requisitos até a V0C. No entanto, mesmo nesse caso, não é fácil incluir novos requisitos em função das ponderações já realizadas. De fato, alguns autores apresentam a possibilidade de alterar os requisitos em fases mais avançadas do PDP (PAHL; BEITZ, 1996; JIAO; TSENG, 1999; CREVELING; SLUTSKY; ANTIS, 2003; ROZENFELD et al., 2006), mas existem dificuldades para avaliar os reais impactos dessa mudança sobre os demais requisitos do projeto.

Um exemplo de gerenciamento estruturado dos requisitos acontece no DSI, cuja fase inicial 
recebe o nome de Engenharia de Requisitos (ER) (SOMMERVILLE, 2007). A ER determina e especifica o que um sistema deve fazer, bem como as circunstâncias sob as quais deve operar, cobrindo todas as atividades que envolvem o levantamento, a documentação e a manutenção dos requisitos (KOTONYA; SOMMERVILLE, 2000). A ER está no centro do desenvolvimento de sistemas computacionais, fazendo a ligação entre os desejos e as restrições dos stakeholders e sua realização em sistemas que, inevitavelmente, combinam tecnologia e processos humanos dentro de um contexto social e organizacional (PARVIAINEN; TIHINEN; SOLINGEN, 2005) e pode ser considerada a primeira fase do processo de desenvolvimento de software (KOTONYA; SOMMERVILLE, 2000; ALVES, 2001; YOUNG, 2003; PARVIAINEN; TIHINEN; SOLINGEN, 2005; SOMMERVILLE, 2007).

0 processo de ER é alimentado por diferentes fontes de informações, entre as quais estão os sistemas existentes, as necessidades dos stakeholders, as necessidades organizacionais, as leis e regulamentos, e as informações de domínio. Como saídas do processo estão os requisitos acordados, as especificações e os modelos de sistema (KOTONYA; SOMMERVILLE, 2000; YOUNG, 2003). Sommerville (2007) esclarece que esse processo não é linear, sendo representado mais adequadamente como uma espiral, em que as diferentes atividades são repetidas iterativamente até que não haja inconsistências. As etapas básicas do processo de ER são: i) elicitação ou levantamento dos requisitos; ii) análise e negociação dos requisitos; iii) documentação dos requisitos; e iv) validação dos requisitos (KOTONYA; SOMMERVILLE, 2000).

A elicitação dos requisitos é um processo de descoberta dos requisitos para um sistema por meio da identificação das necessidades das diferentes classes de usuários (ALVES, 2001), bem como de outras fontes, como documentos do sistema, do domínio de aplicação e de pesquisas de mercado, da mesma forma como acontece no PDP tradicional. Young (2003) ressalta, ainda, a importância de identificar requisitos do negócio durante a elicitação, de forma que o sistema de informação desenvolvido possa contribuir efetivamente para o alcance dos objetivos da organização.

Além dos requisitos levantados diretamente das fontes, alguns novos podem ser obtidos a partir do esclarecimento de requisitos inicialmente mal formulados (da mesma forma como acontece no PDP) ou por meio de técnicas de derivação, como a proposta por Loucopulos e Karakostas* (1995

* LOUCOPULOS, P.; KARAKOSTAS, V. Systems requirements engineering Londres: McGraw Hill, 1995. apud KOTONYA; SOMMERVILLE, 2000). A partir da identificação de objetivos do sistema, estes são decompostos em subobjetivos e, consequentemente, em requisitos não funcionais, uma vez que estão associados a objetivos e não a funções técnicas. Os requisitos obtidos por esse processo, assim como qualquer requisito, devem ser objetivos e verificáveis. De acordo com Kotonya e Sommerville (2000), um requisito não funcional é considerado objetivo quando apresenta um processo pelo qual possa ser testado, sem expressar um desejo, um alvo ou uma opinião individuais.

A etapa seguinte, de análise e negociação, é aquela em que os requisitos são analisados para identificar contradições, relações de dependência e/ ou conflitos, que devem ser resolvidos. Boehm e In (1996) afirmam que, para encontrar o melhor balanço entre os requisitos de qualidade de um produto, é preciso identificar os conflitos entre os atributos de qualidade desejáveis e balanceá-los por meio de priorizações. Sistemas complexos, com diversos stakeholders, podem ser difíceis de balancear e as negociações raramente são conduzidas apenas por argumentos lógicos, mas influenciadas por considerações pessoais, políticas e organizacionais (KOTONYA; SOMMERVILLE, 2000).

$\mathrm{Na}$ etapa de documentação dos requisitos, por sua vez, eles são detalhados apropriadamente e de forma que sejam compreensíveis para todos os stakeholders do sistema. Por esse motivo, os requisitos devem ser documentados por meio de linguagem natural e diagramas. Por fim, a etapa de validação dos requisitos consiste em uma cuidadosa avaliação da consistência e da completude dos requisitos e tem como objetivo detectar problemas no documento de requisitos antes de sua utilização para o desenvolvimento do sistema.

A gestão de requisitos no DSI é geralmente considerada um processo paralelo às etapas anteriores, e está voltada para o gerenciamento de mudanças (KOTONYA; SOMMERVILLE, 2000; ALVES, 2001; PARVIAINEN; TIHINEN; SOLINGEN, 2005; SOMMERVILLE, 2007). De acordo com Kotonya e Sommerville (2000), alterações no documento de requisitos são inevitáveis, seja pela identificação de erros nos requisitos documentados, seja pelo surgimento de novos ao longo do desenvolvimento do sistema. Assim, esse processo tem como objetivo manter uma rastreabilidade das mudanças e assegurar que elas sejam documentadas de maneira controlada (PARVIAINEN; TIHINEN; SOLINGEN, 2005).

Uma abordagem diferente é adotada por Young (2003), que inclui a ER e a gestão de requisitos em um único processo. Baseada na gestão de 
projetos, o autor acrescenta atividades ao processo de requisitos, como uma etapa de planejamento destes, o desenho do processo de requisitos para o projeto e o investimento em atividades relacionadas a eles, considerando o ciclo de vida do sistema. De acordo com o autor, muitos gestores resumem o processo de requisitos à obtenção dos requisitos do sistema e à gestão de mudanças durante o ciclo de vida do projeto. Por esse motivo, o autor apresenta um desdobramento das etapas básicas da ER em diversas atividades, entre as quais estão o entendimento das necessidades de clientes e usuários; a análise, especificação e priorização dos requisitos; a derivação dos requisitos; a alocação destes em subsistemas; o monitoramento e gerenciamento dos requisitos e a validação deles (YOUNG, 2003).

Como apresentado, os diversos modelos de PDP apresentam formas semelhantes de desdobrar os requisitos de um produto, iniciando na identificação das necessidades dos clientes e encerrando na alocação desses requisitos em seus Sistemas, Subsistemas e Componentes (SSCs). No entanto, embora o PDP tenha sido discutido e sistematizado ao longo das últimas décadas, os modelos referenciais analisados não apresentam um método específico para conduzir a gestão de requisitos, a exemplo do que acontece no DSI.

\section{Procedimentos metodológicos}

No que diz respeito ao método de pesquisa, este trabalho apresenta-se como uma pesquisa exploratória, pois pretende proporcionar maior familiaridade com o problema, com vistas a torná-lo mais explícito (DIEHL; TATIM, 2004). Em relação ao procedimento técnico, foi realizada uma pesquisa bibliográfica.

0 método de trabalho está estruturado de acordo com a sequência de quatro etapas representada na Figura 2. A partir da seleção de diferentes modelos de PDP e de ER (1), as atividades relacionadas aos requisitos são comparadas (2) e analisadas (3). Baseado nessa análise é proposta uma sistemática de requisitos para o desenvolvimento de produtos sustentáveis (4).
A etapa 1 deste trabalho apresenta a seleção de diferentes modelos de PDP e ER para comparação, selecionados em função de sua representatividade e/ou diferenciais. A etapa 2 consiste na comparação dos modelos e na identificação de uma sequência de etapas genéricas relacionadas a requisitos. A etapa 3, por sua vez, apresenta uma análise das semelhanças e diferenças dos modelos, bem como a identificação de lacunas existentes com base no referencial teórico apresentado. Por fim, a etapa 4 corresponde à proposta de uma sistemática de requisitos para o desenvolvimento de produtos sustentáveis que preencha as lacunas apontadas na análise da etapa anterior.

\section{Construção da sistemática de gestão de requisitos}

As etapas para a construção da sistemática de gestão de requisitos estão apresentadas a seguir, de acordo com os procedimentos metodológicos descritos anteriormente.

\subsection{Seleção dos modelos representativos}

Os modelos de desenvolvimento de produto utilizados neste estudo foram selecionados por apresentarem diferentes abordagens para o projeto de produtos. Como objetos de estudo foram selecionados três modelos de desenvolvimento de produto, contemplando o enfoque no projeto físico do produto (PAHL et al., 2005), o enfoque na gestão do PDP (ROZENFELD et al., 2006) e o enfoque em aspectos ambientais (ABELE; ANDERL; BIRKHOFER, 2005). Além disso, três modelos específicos foram incluídos, um deles voltado para a qualidade e o gerenciamento de parâmetros críticos (CREVELING; SLUTSKY; ANTIS, 2003) e outros dois modelos de engenharia de requisitos (KOTONYA; SOMMERVILLE, 2000; YOUNG, 2003).

Como já foi mencionado, o processo de engenharia de requisitos constitui apenas uma das fases do desenvolvimento de software e, portanto, seria incorreto realizar uma comparação direta destes com os modelos de desenvolvimento de produto. No entanto, a análise comparativa foi

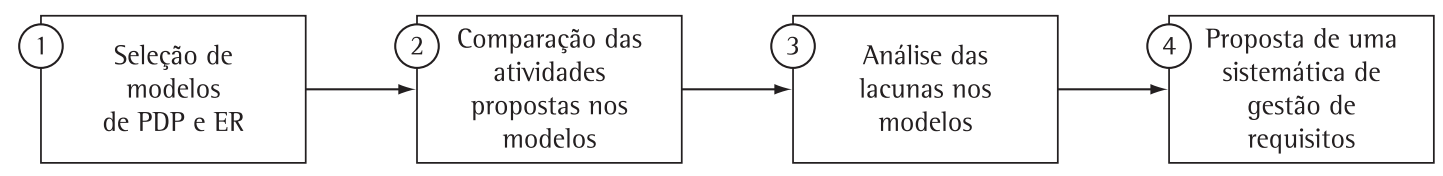

Figura 2. Método de trabalho em quatro etapas. 
realizada apenas entre as atividades dos modelos selecionados que se relacionam aos requisitos, as quais corresponderiam à fase de ER do DSl, caso houvesse uma estrutura definida para a manipulação de requisitos nos demais modelos.

\subsection{Identificação e comparação das atividades dos modelos}

Após a seleção dos modelos, foram identificadas as atividades relativas aos requisitos em cada um deles. Essas informações foram organizadas por similaridade e comparadas, conforme apresentado no Quadro 1. Observa-se que os modelos estudados apresentam muitas atividades em comum, embora com diferente nomenclatura.

A análise comparativa realizada entre os diferentes modelos resultou em uma lista com atividades genéricas que abrangem todas as atividades identificadas nos diferentes modelos, sem considerar particularidades como a gestão de parâmetros críticos (CREVELING; SLUTSKY; ANTIS, 2003) e a análise do ciclo de vida do produto (ABELE; ANDERL; BIRKHOFER, 2005). As atividades resultantes da comparação dos modelos, em destaque à direita no Quadro 1, estão descritas no Quadro 2.

\subsection{Análise das lacunas existentes}

A primeira questão que emerge da comparação entre os modelos refere-se à nomenclatura do processo de requisitos. Embora no DSI seja comum a divisão das atividades relacionadas aos requisitos em dois processos, um de engenharia e outro de gestão de requisitos, essa diferenciação não é um consenso na área, como mostram os modelos de Kotonya e Sommerville (2000) e Young (2003). Assim, considera-se mais adequado adotar apenas a nomenclatura gestão de requisitos, já encontrada na literatura de projeto de produtos (JIAO; TSENG, 1999; McKAY; PENNINGTON; BAXTER, 2001), para denominar todas as atividades de sistematização dos requisitos, incluindo o levantamento, a análise, a priorização, a documentação, a validação, o desdobramento e o controle de mudanças dos requisitos de um sistema-produto ou serviço. lsso se justifica pelo fato de que, neste caso, o termo gestão está empregado como sinônimo de administração, referindo-se à realização eficiente e eficaz das funções de planejamento, organização, liderança e controle (ROBBINS; COULTER, 1998).

Todos os modelos de PDP estudados estão focados no desenvolvimento do produto a partir das necessidades/demandas pelo cliente. De fato, orientar o desenvolvimento de produtos pela VOC é necessário para que os produtos sejam bem-sucedidos comercialmente. No entanto, produtos inovadores não devem estar baseados apenas nas demandas dos clientes diretos, sob o risco de ter o campo de soluções restringido. lsso também se aplica para sistemas-produto sustentáveis, que devem considerar os requisitos de outros stakeholders envolvidos nos demais elementos do sistema, sob o risco de não acessar todas as dimensões da sustentabilidade. À exceção do modelo de Abele, Anderl e Birkhofer (2005), que inclui a voz do meio ambiente (Voice of Environment - VOE) e a voz das regulamentações (Voice of Regulations - VOR) juntamente com a VOC no levantamento de requisitos, e o modelo de Rozenfeld et al. (2006), que menciona os clientes intermediários, os demais modelos de PDP e projeto de produto analisados não consideram as demandas de diversos stakeholders ao longo do processo, como sugerem os modelos de ER. Esta é uma lacuna a ser preenchida.

Da mesma forma, a comparação entre os modelos de PDP sugere que os requisitos relacionados diretamente aos processos produtivos não costumam ser considerados nas fases iniciais de desenvolvimento, nem mesmo no caso do modelo de Abele, Anderl e Birkhofer (2005), que apresenta um enfoque ambiental. Embora seja comum o emprego de ferramentas para facilitar o projeto dos processos de produção durante o desenvolvimento de produtos, elas são comumente empregadas em fases mais avançadas do PDP. Considerando que os sistemas-produtos sustentáveis têm como característica o projeto sistêmico dos diversos elementos relacionados ao ciclo de vida do produto, considera-se necessário que os requisitos dos elementos do sistema também sejam considerados atentamente desde o início do projeto de desenvolvimento. Esta questão é apresentada nos dois modelos de ER analisados, mas a natureza dos processos relacionados ao software é muito diferente dos produtos de manufatura e, portanto, as recomendações apresentadas nestes modelos não podem ser aplicadas diretamente ao projeto de um sistema-produto sustentável. Desse modo, o levantamento e a inserção de requisitos para os diversos elementos do sistema desde o início do projeto apresentam-se como outras lacunas que necessitam ser preenchidas no PDP sustentável.

Todos os modelos incluídos na comparação apresentam atividades sequenciais ao longo das etapas iniciais de desenvolvimento, à exceção do modelo de Kotonya e Sommerville (2000), que é 
iterativo e ocorre ao longo de todo o DSl. A maneira linear como as atividades relacionadas aos requisitos aparecem nos modelos de PDP pode sugerir que o levantamento de requisitos encerra-se com a definição dos requisitos do cliente. Mesmo em um projeto de melhoria incremental em produtos, essa linearidade não é absoluta e novos requisitos podem surgir durante as fases de detalhamento e preparação para a produção. Já em processos de inovação, a iteratividade costuma ser intensa, devido

Quadro 1. Comparação entre as atividades relacionadas a requisitos dos modelos analisados.

\begin{tabular}{|c|c|c|c|c|c|c|c|}
\hline $\begin{array}{c}\text { Enfoque no projeto } \\
\text { do produto } \\
\text { (PAHL et al., 2005) }\end{array}$ & $\begin{array}{l}\text { Enfoque na } \\
\text { gestão do PDP } \\
\text { (ROZENFELD } \\
\text { et al., 2006) }\end{array}$ & $\begin{array}{l}\text { Enfoque na } \\
\text { qualidade } \\
\text { (CREVELING; } \\
\text { SLUTSKY; } \\
\text { ANTIS, 2003) }\end{array}$ & $\begin{array}{l}\text { Enfoque ambiental } \\
\text { (ABELE; ANDERL; } \\
\text { BIRKHOFER, 2005) }\end{array}$ & $\begin{array}{l}\text { Engenharia de } \\
\text { requisitos } \\
\text { (KOTONYA; } \\
\text { SOMMERVILLE, } \\
\text { 2000) }\end{array}$ & $\begin{array}{c}\text { Engenharia de } \\
\text { requisitos } \\
\text { (YOUNG, 2003) }\end{array}$ & $\begin{array}{l}\text { FASES } \\
\text { DO } \\
\text { PDP }\end{array}$ & $\begin{array}{c}\text { ATIVIDADES } \\
\text { RESULTANTES DA } \\
\text { COMPARAÇÃO }\end{array}$ \\
\hline & $\begin{array}{c}\text { Desenho do } \\
\text { ciclo de vida do } \\
\text { produto }\end{array}$ & & & & & \multirow{8}{*}{ 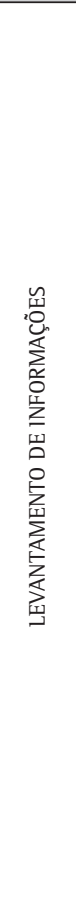 } & $\begin{array}{l}\text { Mapeamento do } \\
\text { cenário }\end{array}$ \\
\hline & $\begin{array}{c}\text { Clasificação dos } \\
\text { clientes }\end{array}$ & & & \multirow{4}{*}{$\begin{array}{l}\text { Elicitação dos } \\
\text { requisitos a } \\
\text { partir de sistemas } \\
\text { existentes, das } \\
\text { necessidades dos } \\
\text { stakeholders, } \\
\text { das necessidades } \\
\text { organizacionais, } \\
\text { das leis e } \\
\text { regulamentos, e } \\
\text { de informações } \\
\text { de domínio }\end{array}$} & $\begin{array}{l}\text { Identificação dos } \\
\text { stakeholders }\end{array}$ & & $\begin{array}{l}\text { Identificação dos } \\
\text { stakeholders }\end{array}$ \\
\hline $\begin{array}{l}\text { Definição dos } \\
\text { requisitos de } \\
\text { mercado }\end{array}$ & $\begin{array}{c}\text { Identificação das } \\
\text { necessidades dos } \\
\text { clientes }\end{array}$ & $\begin{array}{l}\text { Levantamento } \\
\text { da voz do } \\
\text { cliente (Fase de } \\
\text { preparação) }\end{array}$ & $\begin{array}{l}\text { Levantamento da } \\
\text { VOC, dos impactos } \\
\text { ambientais e da } \\
\text { legislação }\end{array}$ & & $\begin{array}{c}\text { Entendimento } \\
\text { das necessidades } \\
\text { de clientes e } \\
\text { usuários }\end{array}$ & & $\begin{array}{c}\text { Levantamento } \\
\text { das necessidades } \\
\text { em requisitos dos } \\
\text { stakeholders }\end{array}$ \\
\hline \multirow[t]{4}{*}{$\begin{array}{l}\text { Definição dos } \\
\text { requisitos de } \\
\text { atratividade para o } \\
\text { segmento/mercado }\end{array}$} & \multirow[t]{2}{*}{$\begin{array}{l}\text { Conversão das } \\
\text { necessidades em } \\
\text { requisitos do } \\
\text { cliente }\end{array}$} & & \multirow{2}{*}{$\begin{array}{l}\text { Desdobramento da } \\
\text { VOC, VOE e VOR } \\
\text { separadamente, de } \\
\text { acordo com a } 1^{\text {a }} \\
\text { matriz do QFD }\end{array}$} & & $\begin{array}{l}\text { 1dentificação } \\
\text { dos requisitos, } \\
\text { incluindo } \\
\text { requisitos do } \\
\text { negócio }\end{array}$ & & \multirow[t]{2}{*}{$\begin{array}{l}\text { Conversão das } \\
\text { necessidades em } \\
\text { requisitos dos } \\
\text { stakeholders }\end{array}$} \\
\hline & & & & & $\begin{array}{c}\text { Esclarecimento } \\
\text { dos requisitos }\end{array}$ & & \\
\hline & & \multirow{3}{*}{$\begin{array}{l}\text { Refino da voz do } \\
\text { cliente }\end{array}$} & $\begin{array}{l}\text { ldentificação das } \\
\text { interrelações das } \\
\text { matrizes da VOC e } \\
\text { da VOE }\end{array}$ & \multirow{5}{*}{$\begin{array}{l}\text { Análise e } \\
\text { negociação dos } \\
\text { requisitos }\end{array}$} & $\begin{array}{l}\text { Análise dos } \\
\text { requisitos }\end{array}$ & & \multirow{3}{*}{$\begin{array}{l}\text { Análise de } \\
\text { conflitos, } \\
\text { negociação e } \\
\text { priorização dos } \\
\text { requisitos }\end{array}$} \\
\hline & $\begin{array}{l}\text { Conversão dos } \\
\text { requisitos de } \\
\text { clientes em } \\
\text { requisitos do } \\
\text { produto }\end{array}$ & & $\begin{array}{c}\text { Desenho de um } \\
\text { portfólio estratégico }\end{array}$ & & $\begin{array}{l}\text { Definição dos } \\
\text { requisitos de } \\
\text { maneira que } \\
\text { eles signifiquem } \\
\text { a mesma coisa } \\
\text { para todos os } \\
\text { stakeholders }\end{array}$ & & \\
\hline $\begin{array}{c}\text { Classificação } \\
\text { dos requisitos } \\
\text { como desejos ou } \\
\text { exigências }\end{array}$ & & & $\begin{array}{l}\text { Análise do portfólio } \\
\text { e geração da lista } \\
\text { de requisitos }\end{array}$ & & $\begin{array}{l}\text { Priorização dos } \\
\text { requisitos }\end{array}$ & & \\
\hline $\begin{array}{l}\text { Definição dos } \\
\text { requisitos técnicos }\end{array}$ & & \multirow{3}{*}{$\begin{array}{l}\text { Geração da lista } \\
\text { de requisitos do } \\
\text { sistema }\end{array}$} & \multirow{2}{*}{$\begin{array}{l}\text { Determinação da } \\
\text { unidade funcional }\end{array}$} & & $\begin{array}{l}\text { Teste e } \\
\text { verificação dos } \\
\text { requisitos }\end{array}$ & \multirow{7}{*}{ 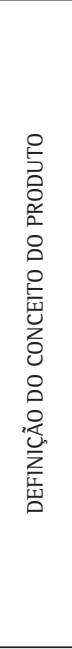 } & \multirow{3}{*}{$\begin{array}{l}\text { Obtenção dos } \\
\text { requisitos do } \\
\text { sistema-produto }\end{array}$} \\
\hline $\begin{array}{c}\text { Complementação } \\
\text { dos requisitos a } \\
\text { partir de técnica de } \\
\text { cenários }\end{array}$ & $\begin{array}{l}\text { Definição das } \\
\text { especificações- } \\
\text { meta }\end{array}$ & & & & $\begin{array}{l}\text { Validação dos } \\
\text { requisitos }\end{array}$ & & \\
\hline $\begin{array}{l}\text { Definiç̧ão da lista } \\
\text { de requisitos e } \\
\text { liberação para a } \\
\text { concepção }\end{array}$ & & & $\begin{array}{l}\text { Definição da lista de } \\
\text { requisitos extendida }\end{array}$ & $\begin{array}{c}\text { Documentação } \\
\text { dos requisitos }\end{array}$ & $\begin{array}{l}\text { Especificação dos } \\
\text { requisitos }\end{array}$ & & \\
\hline \multirow{4}{*}{$\begin{array}{l}\text { Desdobramento da } \\
\text { lista de requisitos } \\
\text { em listas parciais }\end{array}$} & $\begin{array}{l}\text { Modelagem } \\
\text { funcional do } \\
\text { produto }\end{array}$ & $\begin{array}{l}\text { Definição dos } \\
\text { requisitos de } \\
\text { subsistemas }\end{array}$ & $\begin{array}{l}\text { Conversão dos } \\
\text { requisitos em } \\
\text { conceitos }\end{array}$ & \multirow{4}{*}{$\begin{array}{l}\text { Validação dos } \\
\text { requisitos }\end{array}$} & $\begin{array}{l}\text { Derivação dos } \\
\text { requisitos }\end{array}$ & & \multirow{2}{*}{$\begin{array}{l}\text { Conversão dos } \\
\text { requisitos em } \\
\text { funções }\end{array}$} \\
\hline & $\begin{array}{c}\text { Desdobramento } \\
\text { dos requisitos } \\
\text { dos SSCs } \\
\end{array}$ & $\begin{array}{l}\text { Definição dos } \\
\text { requisitos de } \\
\text { submontagem }\end{array}$ & & & $\begin{array}{l}\text { Classificação dos } \\
\text { requisitos }\end{array}$ & & \\
\hline & $\begin{array}{l}\text { Especificações- } \\
\text { meta dos SSCs }\end{array}$ & \multirow{2}{*}{$\begin{array}{l}\text { Definição dos } \\
\text { requisitos dos } \\
\text { componentes }\end{array}$} & & & \multirow{2}{*}{$\begin{array}{l}\text { Alocação dos } \\
\text { requisitos em } \\
\text { subsistemas }\end{array}$} & & \multirow{2}{*}{$\begin{array}{c}\text { Desdobramento } \\
\text { dos requisitos }\end{array}$} \\
\hline & $\begin{array}{l}\text { Concepção do } \\
\text { produto }\end{array}$ & & & & & & \\
\hline \multirow{2}{*}{$\begin{array}{l}\text { Gerenciamento das } \\
\text { listas parciais de } \\
\text { requisitos }\end{array}$} & $\begin{array}{l}\text { Gerenciamento } \\
\text { das mudanças }\end{array}$ & \multirow{2}{*}{$\begin{array}{l}\text { Gestão de } \\
\text { parâmetros } \\
\text { críticos }\end{array}$} & \multirow{2}{*}{$\begin{array}{c}\text { Atualização da } \\
\text { lista de requisitos } \\
\text { extendida durante o } \\
\text { processo }\end{array}$} & \multirow{2}{*}{$\begin{array}{l}\text { Processo de } \\
\text { gestão dos } \\
\text { requisitos }\end{array}$} & $\begin{array}{c}\text { Monitoramento } \\
\text { dos requisitos }\end{array}$ & $\int_{n}^{n}$ & \multirow{2}{*}{$\begin{array}{l}\text { Controle dos } \\
\text { requisitos }\end{array}$} \\
\hline & $\begin{array}{l}\text { Gestão de } \\
\text { parâmetros } \\
\text { críticos }\end{array}$ & & & & $\begin{array}{c}\text { Gerenciamento } \\
\text { dos requisitos }\end{array}$ & $\sum_{\substack{\infty \\
0}}^{n}$ & \\
\hline
\end{tabular}


Quadro 2. Descrição das atividades resultantes da análise dos modelos.

\begin{tabular}{|c|c|}
\hline $\begin{array}{l}\text { Atividades resultantes } \\
\text { da comparação }\end{array}$ & Descrição das atividades \\
\hline Mapeamento do cenário & $\begin{array}{l}0 \text { mapeamento do cenário é importante para o entendimento do contexto social e tecnológico externos à } \\
\text { empresa, bem como da cadeia produtiva envolvida e das relações humanas e de trabalho }\end{array}$ \\
\hline Identificação dos stakeholders & $\begin{array}{l}\text { A partir do desenho da cadeia produtiva, é possível identificar todos os envolvidos, direta ou indiretamente, } \\
\text { com o sistema-produto em todas as fases de seu ciclo de vida. Após haverem sido identificados, os } \\
\text { stakeholders podem ser classificados e avaliados quanto à sua importância e seu poder de decisão em } \\
\text { relação ao produto, o que pode ser útil para a priorização e a negociação dos requisitos }\end{array}$ \\
\hline $\begin{array}{l}\text { Levantamento das necessidades } \\
\text { em requisitos dos stakeholders }\end{array}$ & $\begin{array}{l}\text { Após a identificação dos stakeholders, as informações relativas a suias necessidades, desejos e demandas } \\
\text { devem ser levantadas, em especial daqueles considerados mais importantes }\end{array}$ \\
\hline $\begin{array}{l}\text { Conversão das necessidades em } \\
\text { requisitos dos stakeholders }\end{array}$ & $\begin{array}{l}\text { As informações obtidas anteriormente devem ser convertidas em requisitos, ou seja, organizadas, } \\
\text { categorizadas e estruturadas na forma de requisitos dos stakeholders }\end{array}$ \\
\hline $\begin{array}{l}\text { Análise de conflitos, negociação } \\
\text { e priorização dos requisitos }\end{array}$ & $\begin{array}{l}\text { Os requisitos dos stakeholders devem ser analisados para verificar a existência de conflitos e priorizados } \\
\text { para uma provável seleção e/ou negociação }\end{array}$ \\
\hline $\begin{array}{l}\text { Obtenção dos requisitos } \\
\text { do sistema-produto }\end{array}$ & $\begin{array}{l}\text { Os requisitos dos stakeholders precisam ser convertidos em requisitos do sistema-produto, que são as } \\
\text { características que o produto deve atender ao longo do seu ciclo de vida, desde a obtenção da matéria- } \\
\text { prima até o descarte ou retorno ao processo [este último considerando a filosofia do berço ao berço } \\
\text { (PAUL1, 1998; McDONOUGH; BRANGART, 2002)]. Para tanto, devem ser convertidos em expressões } \\
\text { mensuráveis, analisados, classificados e hierarquizados }\end{array}$ \\
\hline $\begin{array}{l}\text { Conversão dos requisitos } \\
\text { em funções }\end{array}$ & $\begin{array}{l}\text { A equipe de projeto deve definir as funções especificas que o sistema deve possuir para atender aos } \\
\text { requisitos. É feito o desdobramento da função global em subfunções, gerando a estrutura funcional do } \\
\text { sistema-produto. A partir dessa estrutura são identificadas alternativas de solução para cada função e é } \\
\text { definida a arquitetura do produto }\end{array}$ \\
\hline Desdobramento dos requisitos & Após a definição da arquitetura do produto, os requisitos devem ser desdobrados em requisitos dos SSCs \\
\hline Controle dos requisitos & $\begin{array}{l}0 \text { controle dos requisitos deve ser realizado para assegurar que todos os requisitos levantados, priorizados } \\
\text { e acordados nas etapas anteriores estejam contemplados no projeto do sistema-produto. Esta etapa parece } \\
\text { ser mais importante em produtos inovadores, nos quais as mudanças no produto são mais frequentes e } \\
\text { deve ser realizada até o final do projeto }\end{array}$ \\
\hline
\end{tabular}

ao ambiente de incertezas tanto em relação ao desenvolvimento de tecnologias como em relação ao sistema-produto. No entanto, o que costuma acontecer é uma ampliação da fase de levantamento de informações até que haja uma definição mais consistente dos requisitos, como acontece no modelo de Creveling, Slutsky e Antis (2003), havendo o controle dos requisitos críticos por meio da gestão dos parâmetros críticos. Esse controle, no entanto, restringe-se aos requisitos críticos e não contempla os demais. Portanto, a presença de mecanismos para aumentar a iteratividade da gestão de requisitos, bem como para facilitar a análise de conflitos e o controle de alterações nos requisitos ao longo do $\mathrm{PDP}$, apresenta-se como outras lacunas no desenvolvimento de sistemasprodutos sustentáveis.

Por fim, a análise sugere, em função da diversidade de modelos de referência comparados, que a inserção de requisitos do negócio no PDP e no DSI não é uma prática corriqueira. Apenas o modelo de ER proposto por Young (2003) considera, formalmente, a importância de assegurar o alcance dos objetivos estratégicos corporativos por meio dos requisitos. De acordo com esse autor, os sistemas de informação devem colaborar para que a empresa atinja seus objetivos de negócio. No entanto, embora o modelo mostre a possibilidade de alinhamento do produto ao negócio, não é a respeito dos objetivos estratégicos do desenvolvedor que ele trata, mas dos objetivos estratégicos da empresa cliente, uma vez que o projeto de software é feito sob demanda. É importante lembrar que há um consenso entre os autores da área de PDP sobre a necessidade de alinhar o desenvolvimento do produto aos objetivos estratégicos da empresa, embora mecanismos formais e estruturados para garantir esse alinhamento não estejam descritos na literatura consultada.

A literatura demonstra que os requisitos do negócio podem ser derivados diretamente dos objetivos estratégicos ou organizacionais (YOUNG, 2003; CHESBROUGHT; SCHWARTZ, 2007). Os objetivos do negócio são, geralmente, definidos durante o planejamento do negócio, que ocorre em diferentes níveis na organização. Em um nível superior, é realizado o planejamento estratégico (PE), que tem um impacto significativo em toda a organização e objetivos de longo prazo bem definidos (CARAVANTES; PANNO; KLOECKNER, 2005). De acordo com Pagnoncelli e Vasconcellos (1992), o PE envolve a definição do negócio, da missão e dos princípios organizacionais, além de 
uma análise do ambiente interno e externo e a definição de objetivos e estratégias.

0 planejamento nos níveis tático e operacional, por sua vez, está voltado para a implementação das políticas, estratégias e objetivos definidos no PE (CARAVANTES; PANNO; KLOECKNER, 2005). Os objetivos desses níveis de planejamento são definidos pelas gerências intermediárias e operacionais, dentro dos respectivos setores organizacionais. Embora todos os setores devam fazer seus próprios planejamentos táticos e operacionais, alguns têm maior impacto sobre os resultados das empresas. Para a indústria de manufatura, por exemplo, o processo de mercado, o processo de desenvolvimento de produtos/serviços e a produção são considerados processos-chave, sendo os objetivos específicos desses processos importantes para atingir os objetivos estratégicos da organização (SLACK; CHAMBERS; JOHNSTON, 2002). Portanto, para garantir o alinhamento dos produtos desenvolvidos, principalmente sistemasproduto sustentáveis, às definições estratégicas organizacionais, é necessário ancorar os requisitos do produto nos requisitos do negócio derivados ou originados dos objetivos estratégicos e táticooperacionais da organização.

A inexistência dessa fase nos modelos estudados representa-se, na opinião destas autoras, como outra lacuna a ser preenchida por uma sistemática para a gestão de requisitos no PDP sustentável, visto que as dimensões ambiental e econômica estão relacionadas diretamente ao produto físico. A dimensão social, no entanto, está ligada ao negócio e ao processo produtivo, e o produto deve ser ancorado nas definições estratégicas dessa dimensão, para assegurar o seu alcance.

\subsection{Proposta da sistemática de gestão de requisitos}

A princípio, a sequência de atividades originada da comparação dos modelos poderia ser utilizada diretamente para a gestão de requisitos no PDP. Neste caso, no entanto, as lacunas identificadas no modelo não seriam efetivamente preenchidas. Além disso, as atividades propostas nos modelos partem da definição do cenário para o sistema-produto, o que pressupõe que alguma oportunidade tenha sido identificada, anteriormente, em nível estratégico para que um cenário seja desenhado. Conforme mencionado, a fase que antecede a identificação do cenário não é explicada nos modelos, embora os autores mencionem a necessidade de alinhar o processo aos objetivos do negócio, como ponto de apoio para o desenvolvimento do produto.

Em se tratando de um produto sustentável, a preocupação é ainda maior, porque é necessário atender, pelo menos, as dimensões econômica, ambiental e social. Assim, pode-se considerar que a existência de objetivos estratégicos de negócio definidos para todas as dimensões da sustentabilidade constitui-se como uma premissa para o desenvolvimento de um sistema-produto efetivamente sustentável. Dessa forma, é necessário detalhar uma etapa anterior à proposta nos modelos dos autores investigados, na qual sejam gerados os requisitos do negócio sustentável.

A partir da lista de atividades e das lacunas identificadas, foi proposta a sistemática para a gestão de requisitos representada na Figura 3, que mostra as etapas sugeridas, os documentos resultantes de cada etapa e sua interação com as fases do PDP. A figura apresenta, ainda, as relações com os processos de planejamento estratégico e de desenvolvimento tecnológico, bem como a possibilidade de integração das informações de todos esses processos por meio de uma base de dados única.

Essa sistemática apresenta-se dividida em três etapas: duas relacionadas ao negócio e outra relacionada ao sistema-produto. São elas:

- Etapa 0: definição dos objetivos de sustentabilidade do negócio;

- Etapa 1: definição dos requisitos do negócio; e

- Etapa 2: definição dos requisitos do sistemaproduto sustentável.

A primeira etapa é, na verdade, uma condição para a etapa seguinte, motivo pelo qual foi denominada etapa 0 . Nela, os objetivos do negócio (dos níveis estratégico e tático-operacional) devem ser desdobrados em objetivos econômicos, ambientais e sociais, assegurando um ambiente viável para o desenvolvimento do sistema-produto sustentável. Em outras palavras, permite desenvolver sistemas-produto sustentáveis alinhados às estratégias da empresa. 0 Quadro 3 apresenta as principais tarefas envolvidas nesta etapa, que deve ser executada durante os planejamentos estratégico e tático-operacional da empresa.

A etapa 1 consiste no desdobramento dos objetivos do negócio em requisitos do negócio sustentável para o PDP e deve ser realizada em uma fase de planejamento estratégico do desenvolvimento de produtos ou gestão de portfólio na empresa. Seu objetivo é alinhar o PDP aos objetivos estratégicos da organização por meio de um documento de requisitos inicial que deve 


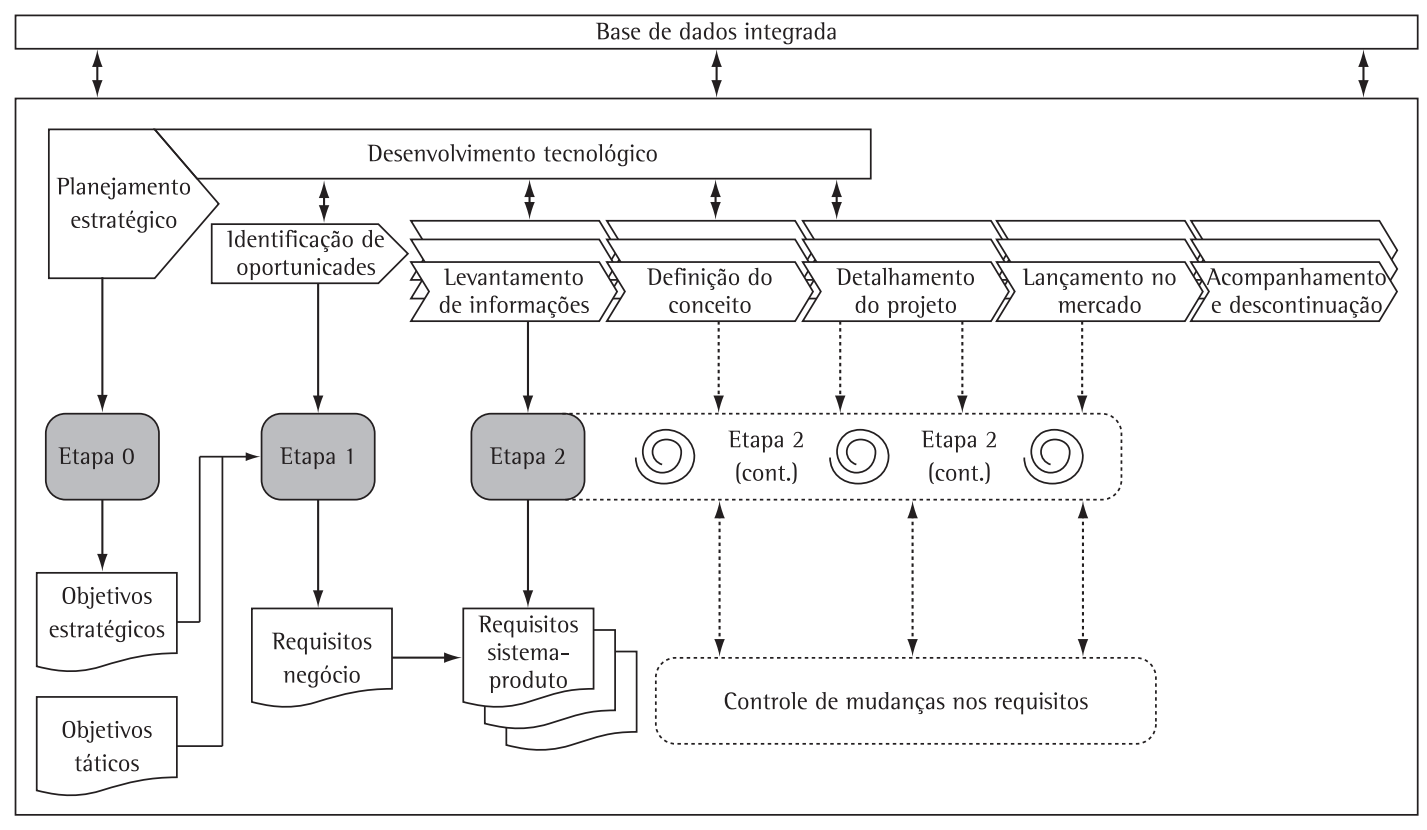

Domínio do negócio

Domínio do sistema-produto

Figura 3. Sistemática de gestão de requisitos proposta para o PDP sustentável.

Quadro 3. Definição dos objetivos de sustentabilidade do negócio.

\begin{tabular}{|c|c|c|}
\hline \multicolumn{3}{|r|}{ ETAPA 0} \\
\hline & Bloco & Tarefas do domínio do negócio sustentável \\
\hline \multirow{5}{*}{ 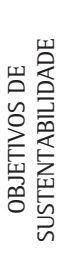 } & \multirow{3}{*}{$\begin{array}{l}\text { Levantamento dos } \\
\text { objetivos estratégicos }\end{array}$} & Mapeamento do cenário do negócio sustentável \\
\hline & & Levantamento das oportunidades de sustentabilidade \\
\hline & & Conversão das oportunidades em macro objetivos e subobjetivos estratégicos de sustentabilidade \\
\hline & Priorização & Priorização dos objetivos estratégicos de sustentabilidade do negócio \\
\hline & $\begin{array}{l}\text { Levantamento dos } \\
\text { objetivos de nível } \\
\text { tático-operacionais }\end{array}$ & Desdobramento dos objetivos e subobjetivos estratégicos em subobjetivos dos níveis tático-operacionais \\
\hline
\end{tabular}

ser utilizado como ponto de partida para o projeto de todos os produtos do portfólio da empresa. 0 Quadro 4 apresenta as principais tarefas envolvidas na etapa 1.

Por fim, a etapa 2 apresenta as tarefas relacionadas a um sistema-produto específico, a serem realizadas a partir das fases iniciais do PDP. Esta etapa consiste em quatro blocos de tarefas: elicitação; análise e negociação; documentação e validação; e controle das mudanças dos requisitos, abrangendo as atividades resultantes da análise comparativa dos modelos e descritas no Quadro 2. Os três primeiros blocos propostos nesta etapa são iterativos, repetindo-se ao longo das fases do projeto daquele sistema-produto, de acordo com o representado na Figura 3. 0 quarto bloco, de controle de mudanças, mostra as tarefas que podem ocorrer em paralelo com as demais tarefas. 0 Quadro 5 apresenta as principais tarefas envolvidas nesta etapa.

\section{Discussão dos resultados}

A sistemática de gestão de requisitos proposta está distribuída nas fases comumente realizadas no PDP e acrescenta novas tarefas, de forma a preencher as lacunas identificadas na análise comparativa. A primeira dessas lacunas refere-se ao alinhamento do PDP aos objetivos estratégicos do negócio sustentável. A inclusão de uma etapa de desdobramento de objetivos estratégicos e táticooperacionais nas três dimensões da sustentabilidade 
Quadro 4. Tarefas de domínio do negócio sustentável.

\begin{tabular}{|c|c|c|}
\hline \multicolumn{3}{|r|}{ ETAPA 1} \\
\hline & Bloco & Tarefas do domínio do negócio sustentável \\
\hline \multirow{4}{*}{ 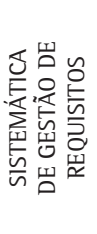 } & Elicitação & Conversão dos objetivos em requisitos de sustentabilidade do negócio (estratégicos e tático-operacionais) \\
\hline & Análise e negociação & $\begin{array}{l}\text { Análise de conflitos, negociação e priorização dos requisitos de sustentabilidade do negócio (estratégicos } \\
\text { e tático-operacionais) }\end{array}$ \\
\hline & $\begin{array}{l}\text { Documentação e } \\
\text { validação }\end{array}$ & Obtenção de documento dos requisitos de sustentabilidade do negócio (estratégicos e tático-operacionais) \\
\hline & Controle de mudanças & Controle das mudanças dos requisitos de sustentabilidade do negócio (alterações no PE da empresa) \\
\hline
\end{tabular}

Quadro 5. Tarefas de domínio do PDP sustentável.

\begin{tabular}{|c|c|c|}
\hline & & ETAPA 2 \\
\hline & Bloco & Tarefas do domínio do negócio sustentável \\
\hline \multirow{9}{*}{ 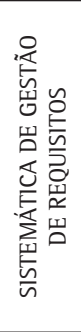 } & \multirow{4}{*}{ Elicitação } & Mapeamento do cenário do sistema produto sustentável \\
\hline & & Identificação dos stakeholders/clientes \\
\hline & & Levantamento das necessidades/demandas dos stakeholders \\
\hline & & Conversão das necessidades/demandas em requisitos do sistema-produto \\
\hline & Análise e negociação & Análise de conflitos, negociação e priorização dos requisitos do sistema-produto \\
\hline & Documentação e validação & Obtenção de documento dos requisitos do sistema/produto \\
\hline & \multirow{3}{*}{ Controle de mudanças } & Conversão dos requisitos em funções e em sistemas, subsistemas e componentes \\
\hline & & Desdobramento dos requisitos \\
\hline & & Controle das mudanças dos requisitos \\
\hline
\end{tabular}

permite, posteriormente, obter requisitos corporativos de sustentabilidade. Juntas, a etapa 0 e a etapa 1 proporcionam o alinhamento dos novos produtos às estratégias corporativas, uma vez que os requisitos de sustentabilidade do negócio são considerados juntamente com requisitos de outras fontes ao longo do PDP. Além do alinhamento ao negócio, essas duas etapas também procuram garantir que as três dimensões da sustentabilidade estejam presentes no projeto do sistema-produto, sendo assim efetivamente sustentável.

É importante ressaltar que os requisitos de sustentabilidade originados do negócio são independentes de um determinado sistema-produto e deveriam orientar o desenvolvimento de todos os produtos da empresa. Assim, se esses requisitos são comuns a todos os produtos da empresa, eles deveriam ser identificados, analisados e priorizados, documentados e validados em uma fase do PDP anterior ao início dos projetos, o que evidencia a necessidade de uma fase de planejamento estratégico do PDP para a sistematização dos requisitos de sustentabilidade do negócio, representada na etapa 1.

Um dos aspectos positivos dessa sistemática é a obtenção de requisitos estratégicos e táticooperacionais de sustentabilidade do negócio. lsso pode ser ainda mais importante no caso de desenvolvimento cooperativo de produtos, uma vez que os requisitos do negócio traduzem a filosofia da organização para todos os parceiros, proporcionando a consideração dos requisitos econômicos, ambientais e sociais do negócio em toda a cadeia, na perspectiva do ciclo de vida do produto.

Esses requisitos do negócio resultantes da etapa 1 são tipicamente não funcionais, uma vez que definem qualidades ou atributos do sistema como um todo e podem constituir restrições para o produto ou para o processo de desenvolvimento. Por esse motivo, são importantes a definição e a distribuição dos objetivos do negócio nas três dimensões da sustentabilidade. Embora o método de desdobramento de requisitos a partir de objetivos não tenha sido criado especificamente para a definição de requisitos do negócio, a abordagem simples permite sua realização mesmo sem um profundo conhecimento de ER.

Além disso, esse desdobramento também pode ser aplicado em empresas que não tenham a filosofia da sustentabilidade, como forma de alinhar o PDP aos objetivos estratégicos da empresa. De fato, quaisquer que sejam os objetivos de negócio de uma empresa, estes poderiam ser desdobrados em requisitos. Para um negócio sem enfoque sustentável, os objetivos do negócio não seriam desdobrados nas três dimensões da sustentabilidade, e no caso de uma empresa voltada para um negócio 
ecologicamente amigável, seriam desdobrados objetivos apenas para as dimensões econômica e ambiental. A obtenção sistemática dos requisitos do negócio poderia assegurar que os produtos, serviços e/ou processos criados pela empresa reflitam o seu posicionamento estratégico e contribuam para atingir os objetivos da organização.

Outra lacuna preenchida pela proposta refere-se à consideração de requisitos para os diversos elementos do sistema-produto desde o início do PDP. Ao derivar requisitos dos objetivos estratégicos e, principalmente, dos objetivos de nível táticooperacional dos processos de mercado, produção, pesquisa e desenvolvimento (P\&D), entre outros, obtêm-se requisitos para diversos elementos do sistema, isto é, requisitos de processo, de materiais, de qualidade, além de requisitos de produto. Como as tarefas de derivação estão contempladas na etapa 0 e etapa 1, anteriores ao projeto de um determinado sistema-produto, esses requisitos dos elementos do sistema serão considerados desde o início do PDP, juntamente com os requisitos de outros stakeholders, que serão levantados na etapa 2. A inclusão de demandas de diversos stakeholders no PDP foi outra lacuna apontada na análise, e as atividades de mapeamento do cenário e identificação dos stakeholders (comuns nos modelos de ER) foram incorporadas como tarefas a serem executadas na etapa de domínio do PDP.

As demais lacunas identificadas na análise comparativa, iteratividade e existência de mecanismos para análise de conflitos e controle de mudanças dos requisitos, foram atendidas pela inclusão de tarefas específicas na etapa 2. Esta etapa deve ser iterativa, especialmente as tarefas dos blocos de elicitação e análise e negociação dos requisitos. Na Figura 3, a espiral sobre a etapa 2 indica as tarefas iterativas, enquanto as tarefas do bloco controle de mudanças, embora pertençam à mesma etapa, aparecem destacadas por ocorrerem em paralelo com as demais.

\section{Considerações finais}

Este trabalho tinha como objetivo propor uma sistemática de requisitos para o desenvolvimento de produtos sustentáveis, de forma a facilitar a inclusão de requisitos ambientais, econômicos e sociais ao projeto, num primeiro momento, e de permitir a rastreabilidade dos mesmos em todas as fases de desenvolvimento. A revisão bibliográfica mostrou que quanto maiores as incertezas em relação ao produto, seja em função da complexidade do sistema-produto ou de um elevado grau de inovação, maiores são as justificativas para uma estruturação na gestão de requisitos.

Além de abarcar todas as atividades presentes nos modelos, as três etapas e 18 tarefas da sistemática proposta preenchem as lacunas deixadas pelos diversos modelos estudados, que são: i) a inclusão de demandas de diversos stakeholders; ii) a consideração de requisitos para os diversos elementos do sistema-produto desde o início do PDP; iii) a inserção de mecanismos para análise de conflitos e controle de mudanças dos requisitos; iv) o aumento na iteratividade da gestão de requisitos; e v) a inserção de requisitos do negócio para alinhar o PDP às estratégias da empresa.

Embora a problemática dos requisitos esteja descrita detalhadamente na literatura de desenvolvimento de software e haja a orientação de incluir requisitos do negócio no projeto, não é claro como isso pode ser implementado. A sistemática proposta neste trabalho contempla as atividades relacionadas a requisitos presentes em diferentes modelos de desenvolvimento de produtos, além de uma etapa estratégica em que os objetivos do negócio são desdobrados até a obtenção de requisitos do negócio sustentável. A inserção dessa etapa estratégica foi considerada essencial, porque se partiu do pressuposto que não é possível desenvolver um produto sustentável fora de um ambiente de negócio sustentável que contemple as três dimensões da sustentabilidade: ambiental, social e econômica. Pode-se concluir que a empresa, ao considerar requisitos de sustentabilidade derivados dos objetivos do negócio durante o PDP, irá desenvolver sistemas-produto sustentáveis automaticamente alinhados aos objetivos corporativos.

Essas considerações, no entanto, precisam ser comprovadas mediante aplicações práticas da sistemática no projeto de diferentes produtos. Neste artigo foi apresentada uma proposição teórica sem a correspondente aplicação prática, o que se deve a restrições de espaço. Os detalhamentos do referencial teórico e da metodologia empregada para a construção do modelo foram considerados contribuições relevantes para a produção científica e acadêmica da área de desenvolvimento de produtos. Outras publicações serão realizadas para ilustrar a aplicação do método em situação real.

É importante ressaltar, ainda, que o modelo proposto apresenta como limitação a base teórica utilizada para a sua construção. As atividades consideradas na análise comparativa são comuns também a outros modelos de PDP, mas é possível que a inclusão de novos modelos possa levar a um resultado diferente em termos de atividades de 
gestão de requisitos. Não há evidências, no entanto, de que essa limitação diminua a aplicabilidade do modelo, uma vez que as particularidades dos modelos não foram consideradas na análise, com o intuito de obter uma sistemática de requisitos aplicável a qualquer PDP.

Como sugestões para trabalhos futuros, estão:

i) o detalhamento das atividades apontadas;

ii) a sugestão de métodos e ferramentas para operacionalizar as atividades propostas; e

iii) a aplicação em casos reais de desenvolvimento de produtos para a comprovação da aplicabilidade da proposta no desenvolvimento de produtos sustentáveis, bem como de produtos tradicionais e em diferentes modelos de PDP.

\section{Agradecimentos}

Os pesquisadores agradecem à Coordenação de Aperfeiçoamento de Pessoal de Nível Superior CAPES o apoio financeiro e a manutenção da bolsa de auxílio.

\section{Referências}

ABELE, E.; ANDERL, R.; BIRKHOFER, H. G. Environmentallyfriendly product development: methods and tools. London: Springer, 2005. http://dx.doi.org/10.1007/b138604

ALVES, C. S. Um método baseado em requisitos não-funcionais para seleção de COTS. 2001. Dissertação (Mestrado em Ciências da Computação)-Universidade Federal de Pernambuco, Recife, 2001.

AKAO, Y. QFD: Past, present, and future. In: INTERNATIONAL SYMPOSIUM ON QFD ’97, Linköping, 1997.

BAXTER, M. Product design: practical methods for the systematic development of new products. London: Chapman \& Hall, 1996.

BOEHM, B.; IN, H. Identifying quality-requirement conflicts. IEEE Software, v. 13, n. 2, p. 25-35, 1996. http://dx.doi. org/10.1109/52.506460

BREZET, H.; HEMEL, C. Ecodesign: a promising approach to sustainable production and consumption. Paris: UNEP, 1997.

CARAVANTES, R. G.; PANNO, C. C.; KLOECKNER, M. C. Administração: teorias e processo. São Paulo: Pearson Prentice Hall, 2005.

CHESBROUGHT, H.; SCHWARTZ, K. Innovating business models with co-development partnerships. Research-Technology Management, v. 50, n. 1, p. 55-59, 2007.

CLAUSING, D. Total quality development: a step-by-step guide to world-class concurrent engineering. New York: ASME, 1994.

COOPER, R. G. New products: the factors that drive success. International Marketing Review, v. 11, n. 1, p.60-76, 1994. http://dx.doi.org/10.1108/02651339410057527

CRAWFORD, C. M.; BENEDETTO, C. A. New products management. 6. ed. Chicago: McGraw-Hill, 2000.

CREVELING, C. M.; SLUTSKY, J.; ANTIS, D. Design for Six Sigma: in technology and product development. Upper Saddle River: Prentice Hall PTR, 2003.
DIEHL, J. C.; BREZET, H. Design for Sustainability: an approach for international development, transference and local implementation. In: INTERNATIONAL CONFERENCE ENVIRONMENTAL MANAGEMENT FOR SUSTAINABLE UNIVERSITIES, 2004, Monterrey. Proceedings... Monterrey: Tecnológico de Monterrey. p. 1-10.

DIEHL, A. A.; TATIM, D. C. Pesquisa em ciências sociais aplicadas: métodos e técnicas. São Paulo: Prentice-Hall Brasil, 2004.

FIKSEL, J. Design for environment: an integrated systems approach. In: INTERNATIONAL SYMPOSIUM ON ELECTRONICS AND ENVIRONMENT, 1993, Arlington. Proceedings... Arlington, 1993. p. 126-131. http://dx.doi. org/10.1109/1SEE.1993.302823

FROSCH, R. A.; GALLOPOULOS, N. Strategies for manufacturing. Scientific American, n. 261, p. 144-152, 1989. http:// dx.doi.org/10.1038/scientificamerican0989-144

GUIMARÃES, L. B. M. A ecologia no projeto de produto: design sustentável, design verde, ecodesign. In: GUIMARÃES, L. B. M. Ergonomia de produto. 5. ed. Porto Alegre: FEENG, 2006.

HALEN, C.; VEZZOLI, C.; WIMMER, R. Methodology for product service system innovation: how to develop clean, clever and competitive strategies in companies. Assen: Koninklijke Van Gorcum, 2005.

HAUSCHILD, M.; JESWIET, J.; ALTING, L. From life cycle assessment to sustainable production: status and perspectives. CIRP Annals - Manufacturing Technology, v. 54, n. 2, p. 1-21, 2005.

INTERNATIONAL ORGANIZATION FOR STANDARDIZATION 1SO. ISO 14040:2006. Disponível em: <http://www.iso.org/ iso/catalogue_detail?csnumber $=37456>$. Acesso em: 10 maio 2009.

JIAO, J.; TSENG, M. M. A requirement management database system for product definition. Integrated manafucturing systems, v. 10, n. 3, p. 126-131, 1999.

JOHANSSON, G. Success factors for integration of ecodesign in product development: a review of state of the art. EnvironmentalManagementandHealth,v.13,n. 1, p.98-107, 2002. http://dx.doi.org/10.1108/09566160210417868

KAZMIERCZYK, P. Manual on the development of cleaner production policies approaches and instruments. Vienna: Unido CP Programme, 2002.

KOTONYA, G.; SOMMERVILLE, 1. Requirements engineering: process and techniques. Chichester: John Wiley \& Sons, 2000.

LABUSCHAGNE, A. C.; BRENT, A. C.; ERCK, R. P. G. van. Assessing the sustainability performances of industries. Journal of Cleaner Production, v. 13, n. 4, p. 373-385, 2005. http://dx.doi.org/10.1016/j.jclepro.2003.10.007

LUTTROPP, C.; KARLSSON, R. The conflict of contradictory environmental targets. In: INTERNATIONAL SYMPOSIUM ON ENVIRONMENTAL CONSCIOUS DESIGN AND INVERSE MANUFACTURING, 2., 2001, Tokyo. Proceedings...

MANZINI, E.; VEZZOLI, C. O desenvolvimento de produtos sustentáveis: os requisitos ambientais dos produtos industriais. São Paulo: USP, 2005.

MARX, A. M. Proposta de método de gestão de requisitos para o desenvolvimento de produtos sustentáveis. 2009. $133 \mathrm{f}$. Dissertação (Mestrado em Engenharia de Produção)Universidade Federal do Rio Grande do Sul, Porto Alegre, 2009.

MAXWELL, D.; VORST, R. Developing sustainable products and services. Journal of Cleaner Production, n. 11, p. 883-895, 2003. http://dx.doi.org/10.1016/S0959-6526(02)00164-6 
McDONOUGH, W.; BRAUNGART, M. Cradle to cradle: remaking the way we make things. New York: North Point Press, 2002.

McKAY, A.; PENNINGTON, A.; BAXTER, J. Requirements management: a representation scheme for product specifications. Computer-Aided Design, v. 33, p. 511-520, 2001. http://dx.doi.org/10.1016/S0010-4485(01)00050-1

MONT, O. K. Clarifying the concept of product-service system. Journal of Cleaner Production, v. 10, n. 3, p. 237-245, 2002. http://dx.doi.org/10.1016/S0959-6526(01)00039-7

PAGNONCELLI, D.; VASCONCELLOS FILHO, P. Sucesso empresarial planejado. Rio de Janeiro: Qualitymark, 1992.

PAHL, G.; BEITZ, W. Engineering design: a systematic approach. London: Springer, 1996.

PAHL, G. et al. Projeto na engenharia: fundamentos do desenvolvimento eficaz de produtos, métodos e aplicações. São Paulo: Edgar Blücher, 2005.

PARVIAINEN, P.; TIHINEN, M.; SOLINGEN, R. Requirements engineering: dealing with the complexity of Sociotechnical Systems Development. In: MATÉ, J. L.; SILVA, A. Requirements engineering for sociotechnical systems. Hershey: Information Science, 2005.

PAULl, G. Upsizing: como gerar mais renda, criar mais postos de trabalho e eliminar a poluição. Porto Alegre: Fundação Zeri Brasil; L\&PM, 1998.

ROBBINS, S. P.; COULTER, M. Administração. 5. ed. Rio de Janeiro: Prentice-Hall do Brasil, 1998.

ROOZENBURG, N. F. M.; EEKELS, J. Product design fundamentals and methods. Chichester: John Wiley and Sons, 1996.

ROZENFELD, H. et al. Gestão de desenvolvimento de produtos: uma referência para a melhoria do processo. São Paulo: Saraiva, 2006.

SELIGER, G.; KERNBAUM, S.; ZETTL, M. Remanufacturing approaches contributing to sustainable engineering. Gestão \& Produção, v. 13, n. 3, p. 367-384, 2006. http://dx.doi. org/10.1590/S0104-530X2006000300002
SELIGER, G.; MERTINS, K. Sustainability in production engineering. In: BMBF - FORUM FOR SUSTAINABILITY, 4., Leipzig, 2007. Presentation. Disponível em: <http:// www.fona.de/pdf/forum/2007/C_5_02_Seliger_abstract_ L2L_2007.pdf>. Acesso em: 25 jul. 2008.

SEYFANG, G. Environmental mega-conferences: from Stockholm to Johannesburg and beyond. Global Environmental Change, v. 13, p. 223-228, 2003. http:// dx.doi.org/10.1016/S0959-3780(03)00006-2

SLACK, N.; CHAMBERS, S.; JOHNSTON, R. Administração da produção. 2. ed. São Paulo: Atlas, 2002.

SOMMERVILlE, 1. Engenharia de software. 8. ed. São Paulo: Pearson Addison-Wesley, 2007.

TIBBEN-LEMBKE, R. S. Life after death: reverse logistics and the product lifecycle. International Journal of Physical Distribution \& Logistics Management, v. 32, n. 3, p. 223-244, 2002. http://dx.doi.org/10.1108/09600030210426548

TSENG, M. M.; JIAO, J. A variant approach to functional requirement acquisition for evolutionary product design. Journal of Engineering Design, v. 8, n. 4, p. 329-40, 1997. http://dx.doi.org/10.1080/09544829708907969

TUKKER, A.; TISCHNER, U. Product-services as a research field: past, present and future. Reflections from a decade of research. Journal of Cleaner Production, v. 14, p. 1552-1556, 2006. http://dx.doi.org/10.1016/j.jclepro.2006.01.022

ULRICH, K. T.; EPPINGER, S. D. Product design and development. Boston: Irvin McGraw-Hill, 2000.

WORLD COMMISSION ON ENVIRONMENT AND DEVELOPMENT - WCED. Our common Future. 1987. Disponivel em: <http:// www.un-documents.net/wced-ocf.htm>. Acesso em: 10 set. 2008.

WEENEN, J. C. Towards sustainable product development. Journal of Cleaner Production, v. 3, n. 1-2, p. 95-100, 1995. http://dx.doi.org/10.1016/0959-6526(95)00062-J

YOUNG, R. The requirements engineering handbook. Norwood: Artech House, 2003.

\title{
Proposition of a requirements management framework for sustainable product development
}

\begin{abstract}
The aim of this paper is to propose a framework to support the development of sustainable products using a requirements management approach. The requirements management framework proposed presents three stages and eighteen tasks to ensure that the new products design reflect the organization commitment to environmental, economic and social sustainability dimensions. Stages one and two are of strategic nature and the objective is to define the business requirements. Stage three consists in a set of activities concerned with the requirements of the sustainable product-system being designed. The framework contributes to product development management literature as: the inclusion of diverse stakeholders' requirements for the product-system, the inclusion of requirements analysis and control of changes, the increment of the requirements management iteration and the inclusion of business requirements to align the New Product Development to business strategies. The proposed method generality makes it a tool for organizations compromised with sustainability, as well as for organizations which focus other objectives in their product development.
\end{abstract}

\section{Keywords}

Sustainability. Requirements management. New Product Development. 